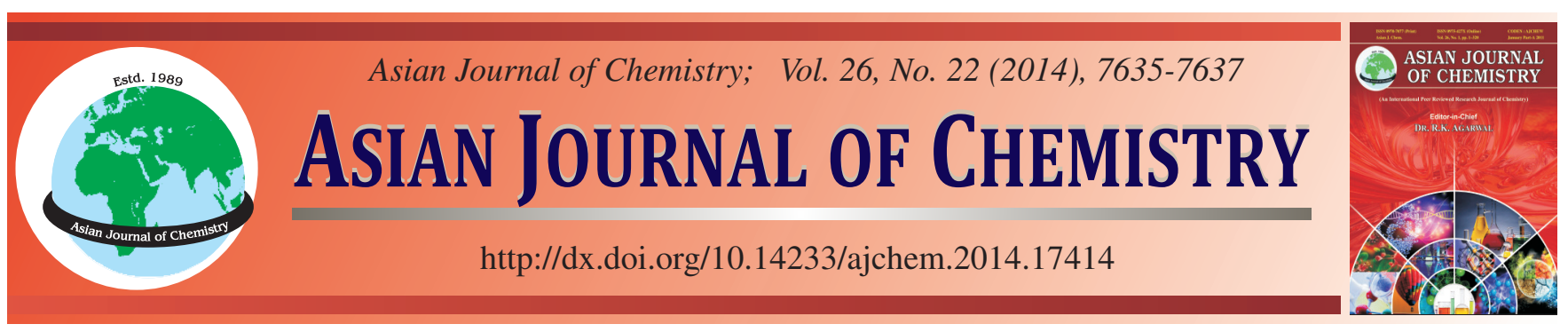

\title{
Shaped-Controlled Synthesis of Nanosized Cuprous Oxides by Hydrothermal Oxidation Method
}

\author{
Nguyen Tien ThaO ${ }^{1,2, *}$ and Mai Quang TuOng ${ }^{2}$
}

${ }^{1}$ Faculty of Chemistry, VNU University of Science, Vietnam National University, Hanoi 10999, Vietnam

${ }^{2}$ VNU University of Science, 19-Le Thanh Tong ST, Hanoi 10999, Vietnam

*Corresponding author: Fax: +84 4 38241140; Tel: +84 4 38253503; E-mail: ntthao@vnu.edu.vn

\begin{abstract}
Nanoscaled cuprous oxides were synthesized using the reaction between metallic copper and aqueous hydrogen peroxide solution in isothermal conditions. The resultant solids are characterized by XRD, SEM, TEM, BET techniques. The obtained products are mainly cuprous oxides with different morphologies. The size, shape and aspect ratio of products can be readily controlled by aging time and additive amounts. The present controlled synthesis method yield some kinds of highly crystalline metal oxide nanocrystals. An introduction of $\mathrm{HCOOH}$ additive into reaction mixture would significantly affect the controllable size, shape and yield of $\mathrm{Cu}_{2} \mathrm{O}$.
\end{abstract}

Keywords: Controlled synthesis, $\mathrm{Cu}_{2} \mathrm{O}$, Nanoparticles, Nanostructured oxide.

\section{INTRODUCTION}

Since the shape, size and material morphologies is significantly related with physico-chemical properties ${ }^{1-3}$, the synthesis of metal oxide particles with controllable shape, size and phase has recently played an important role in nanomaterials chemistry.

Numerous nanostructured oxides synthesized in typical conditions has been exhibited several excellent electronic, optical, magnetic and catalytic properties that are distinct as compared to their corresponding bulk materials. For a typical example, cuprous oxide has been used for making solar cells $\mathrm{s}^{1,2}$, nanomagnetic devices ${ }^{3}$, chemical industry ${ }^{4}$, biosensors ${ }^{5}$. The abnormal properties of three-dimensional architecture assemblies are raised from the mutual order interparticle arrangements ${ }^{6,7}$. To achieve desired architecture, control of the crystallinity of materials to obtain either single crystals or polycrystals is still a challenging for synthetic scientists. It is noted the strong relationship between product morphologies and experimental parameters ${ }^{8}$. In the hydrothermal synthesis, the synthetic conditions are crucial for controlling nucleation and growth in manipulating the size, shape and phase of the resulting nanostructures. The formation of several metal oxide nanocrystals can be obtained by the interaction between metals and oxidants, in which the growth of product nanocrystals occurs at the expense of larger metal bulk ${ }^{9}$. The resultant system composed of two or more different components has attracted particular interest because of their unique properties are not usually attainable in single components. Metal oxides highly dispersed on support surfaces show active catalysts for a variety of reactions ${ }^{4,8}$. The origins of their high catalytic activity come presumably from one or more of three contributions: (i) presence of low coordinative numbers; (ii) charge transfer between the oxide and the metal; (iii) quantum size effect ${ }^{1,5,6,10}$.

This paper presents an environmentally friendly route for the synthesis of $\mathrm{Cu}_{2} \mathrm{O}$ particles, examining the influence of experimental conditions on the morphology of $\mathrm{Cu}_{2} \mathrm{O}$ nanocrystals.

\section{EXPERIMENTAL}

Synthesis of mixed copper oxides: In a typical synthesis, $1 \mathrm{~g}$ of metallic copper powder (Sigma-Aldrich) was added into $10 \mathrm{~mL}$ of distilled water with magnetic stirring. Then, $60 \mathrm{~mL}$ of $30 \% \mathrm{H}_{2} \mathrm{O}_{2}$ was added dropwise and the reaction stirred for $2 \mathrm{~h}$. The mixture was placed in a $100 \mathrm{~mL}$ autoclave with a Teflon liner. The autoclave was kept at $80{ }^{\circ} \mathrm{C}$ for 2-24 days and then air-cooled to room temperature. The resulting precipitates were collected and washed with distilled water several times and then dried at $80^{\circ} \mathrm{C}$ for $12 \mathrm{~h}$.

Powder X-ray diffraction (XRD) patterns were recorded on a D8 Advance-Bruker instrument using $\mathrm{CuK}_{\alpha}$ radiation $(\lambda=$ $1.59 \mathrm{~nm}$ ). The scanning electron microscopy (SEM) microphotographs were obtained in a JEOS JSM-5410 LV. The nitrogen physisorption was measured at $77 \mathrm{~K}$ on an Autochem II 2920 (USA). 


\section{RESULTS AND DISCUSSION}

The preparation of metal oxides was carried out under hydrothermal oxidation conditions to obtain the nanostructured products through the reaction between metal powder and aqueous hydrogen peroxide solution. Table- 1 collects a set of samples aged at $80{ }^{\circ} \mathrm{C}$ in reported conditions.

\begin{tabular}{cccl}
\multicolumn{5}{c}{ TABLE-1 } \\
\multicolumn{5}{c}{ SAMPLE PREPARATION AND PHASE RESULTANTS } \\
\hline Sample & $\begin{array}{c}\text { Aging time } \\
\text { (day) }\end{array}$ & $\begin{array}{c}\mathrm{HCOOH} \\
\text { additive }\end{array}$ & \multicolumn{1}{c}{ Products } \\
\hline 1 & 0 & - & $\mathrm{Cu}$ \\
2 & 2 & - & $\mathrm{Cu}, \mathrm{Cu}_{2} \mathrm{O}$ \\
3 & 6 & - & $\mathrm{Cu}, \mathrm{Cu}_{2} \mathrm{O}$ \\
4 & 12 & - & $\mathrm{Cu}, \mathrm{Cu}_{2} \mathrm{O}$ \\
5 & 24 & - & $\mathrm{Cu}, \mathrm{Cu}_{2} \mathrm{O}, \mathrm{CuO}$ \\
6 & 12 & $0.5 \mathrm{~mL}$ & $\mathrm{Cu}, \mathrm{Cu}_{2} \mathrm{O}$ \\
7 & 12 & $1.0 \mathrm{~mL}$ & $\mathrm{Cu}, \mathrm{Cu}_{2} \mathrm{O}, \mathrm{CuO}$ \\
8 & 12 & $1.5 \mathrm{~mL}$ & $\mathrm{Cu}, \mathrm{Cu}_{2} \mathrm{O}, \mathrm{CuO}$ \\
\hline
\end{tabular}

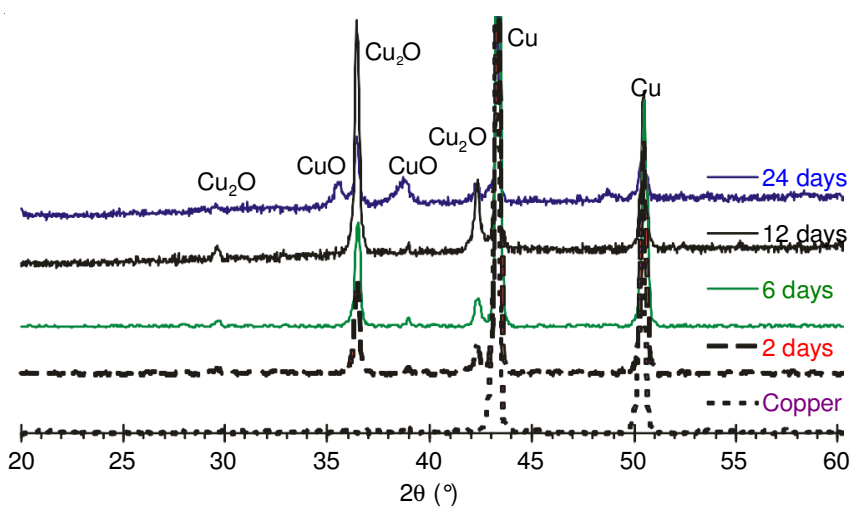

Fig. 1. XRD patterns for samples aged at different aging times

All synthesized samples were recorded X-ray diffractograms to investigate the phase structure. For comparison, the XRD pattern for metallic copper (Sample 1) was also reported in Fig. 1. When copper contacts with aqueous $\mathrm{H}_{2} \mathrm{O}_{2}$ solution in an sealed autoclave, surface metallic copper was easily oxidized to cuprous oxide and thus the growth of copper oxide crystallites is proportional with the aging time ${ }^{9,11}$. After 2 days, XRD pattern for sample 2 appears a set of 20-theta at 29.81, 36.38 and $42.35^{\circ}$. These reflection angles are, respectively indexed to the (110), (111) and (200) planes, which are typically characteristic for the cubic $\mathrm{Cu}_{2} \mathrm{O}$ phase [Joint Committee on Powder Diffraction Standards (JCPDS) Card No. 01-0770199] with the lattice constant $\mathrm{a}=4.2580 \AA$. Moreover, the broadening and well-resolved diffraction peaks can be attributed to the nanoscale nature and high crystallinity of $\mathrm{Cu}_{2} \mathrm{O}^{1,3,4,6}$. These diffraction line intensities increase dramatically with the aging time from 12 to 24 days, indicating an increased yield and the growth in the size of $\mathrm{Cu}_{2} \mathrm{O}$ after a longer period of aging ${ }^{5,9}$. Furthermore, aging the samples up to 24 days leads to the appearance of $\mathrm{CuO}$. Fig. 1 shows two small reflection lines at 35.6 and $38.9^{\circ}$ responsible for the monoclinic $\mathrm{CuO}$ (JCPDS Card No. 00-003-0884) when the sample aged for 24 days (Sample 5) $)^{2,7}$. This is consistent with the noticeable differentiations in the product morphologies observed by SEM technique.
Fig. 2 shows some scanning electron microscopy (SEM) images of the representative samples. For the starting copper powder (Fig. 2A), it is observed the larger particles of a few microns in diameter. The particles are not uniform in size and stick together. The copper particle size gradually decreases in the hydrothermal oxidation conditions for 6 days and simultaneously there appear the nanoneedles on the copper particle surface (Fig. 2B). At higher magnification levels, these needles were found to have the mean width $\mathrm{x}$ thickness of $30 \mathrm{~nm} \times 20$ $\mathrm{nm}$. They are firmly assigned to the crystalline $\mathrm{Cu}_{2} \mathrm{O}$ products, in accordance with the XRD analysis (Fig. 1). These nanoneedles are no longer present when the sample was collected after 12 days. Instead, the nanostrips are observed (Fig. 2C). Each individual nanostrip has an average diameter of 10-20 $\mathrm{nm}$ and a length of 70-100 $\mathrm{nm}$. A careful observation of the enlarged SEM images in several parts of this sample clearly indicates that a nanostrip is constructed by the combination of primary spherical nanoparticles ${ }^{5}$. Furthermore, nanostrips attached with each other to construct the bundles. The formation of uniformly assembled nanostrips of $\mathrm{Cu}_{2} \mathrm{O}$ would expect to have a rather low external surface area since the ordered arrangement of highly spherical particles reaches the closest packing $^{13}$. Indeed, nitrogen adsorption-desorption isothermal curve of sample 4 shows no hysteris loop which is essentially characteristic for the nonporous materials (type II). The specific surface area determined by BET method is only $1 \mathrm{~m}^{2} / \mathrm{g}$ (Fig. 3). In consistent with $X$-ray analysis, the nanostrips are cuprous oxide particles grown up on the surface of the metallic particles in certain dimensions ${ }^{9}$. In order to increase the yield of cuprous oxide, the preparation was lasted to 24 days. Fig. 2D displays the mixed product composed of nanosized particles and the nanoplates ${ }^{10,11}$. In line with the trend of the formation of nanoparticles as increased aging time (Fig. 2B and 2C), it is suggested that the nanosized particles observed in Fig. 2D are attributed to the cuprous oxide phase. The nanospheres have the average diameter of 20-25 nm (Fig. 2D). In addition, SEM image of sample 5 also appears the nanoplates which are

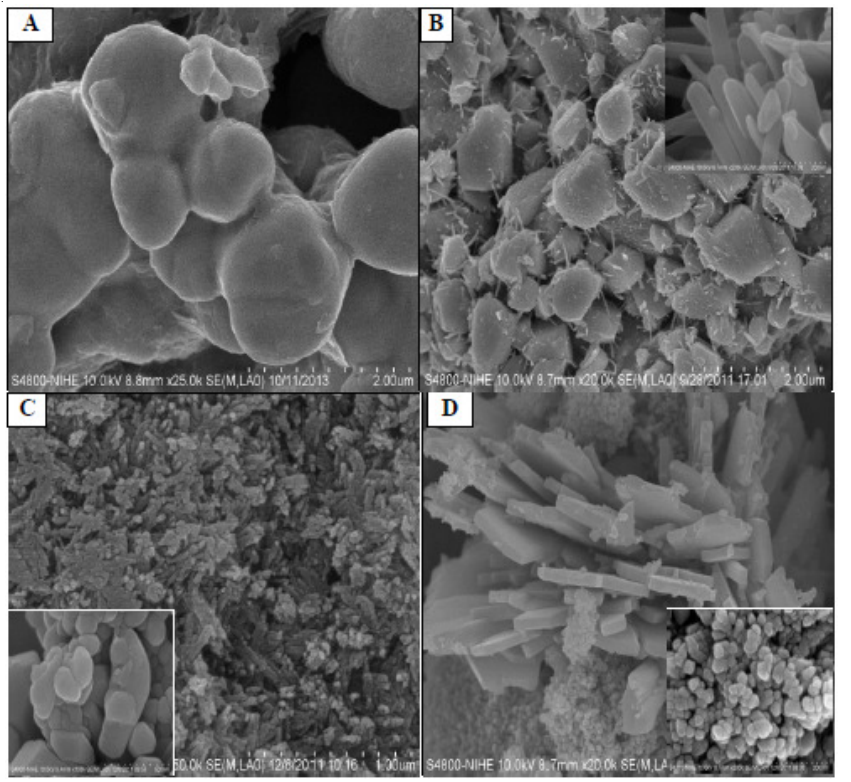

Fig. 2. SEM photographs of sample 1 (A), sample 3 (B), sample 4 (C), and sample 5 (D) 
responsible for the cupric oxide phase as consistent with the

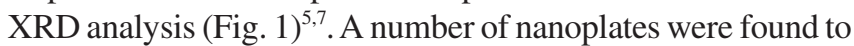
be highly oriented and extended outward from the center ${ }^{9,13,14}$.

Due to the formation of mixed products for sample 5, it is expected to existence of some slit-shaped spaces between the nanoparticles and nanoplates ${ }^{7,10,12}$. Fig. 3 shows a nitrogen adsorption/desorption isotherm of sample 5 having a very narrow hysteris loop in the relative pressure range of 0.45 1.00. This observation indicates the condensation of nitrogen in the voids formed between the nanospheres and nanoplates (Fig. 2D). The BET area in the latter sample is $6.5 \mathrm{~m}^{2} / \mathrm{g}$.

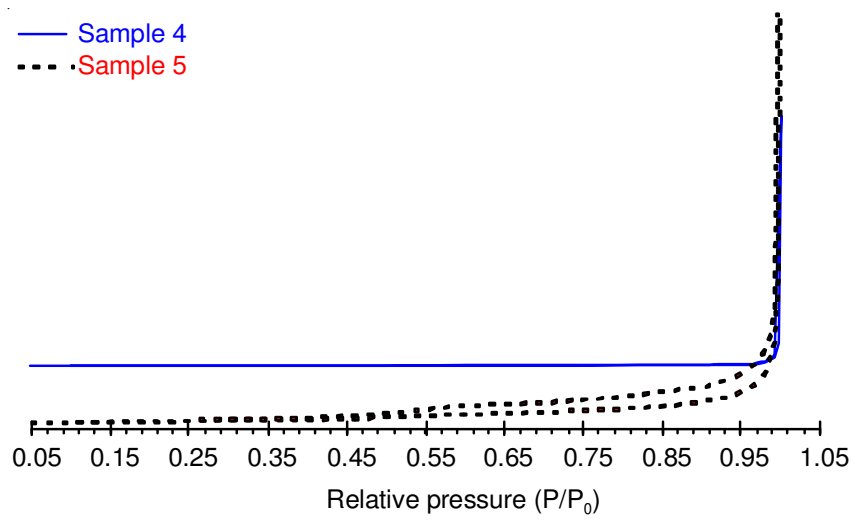

Fig. 3. Nitrogen adsorption-desorption isothermal curves

In order to improve the amount of cuprous oxide product, we have added a small amount of $85 \mathrm{wt}$. \% HCOOH solution into the mixed solution (Table-1). The X-ray diffraction patterns for the resultant powder were reported in Fig. 4.

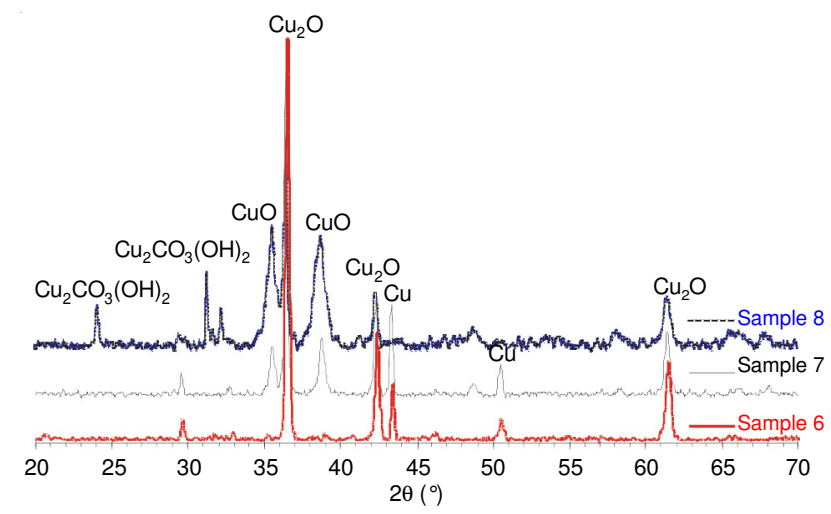

Fig. 4. XRD patterns for samples 6-8

As seen in Fig. 4, the major components in the mixture are only $\mathrm{Cu}_{2} \mathrm{O}$ and $\mathrm{CuO}$ in addition to the small $\mathrm{Cu}$ remained as the synthesis is carried out in the presence of $\mathrm{HCOOH}$ additive (Table$1)^{5,7,13}$. For the sample 6 , XRD pattern displays well-resolved diffraction peaks representing to the $\mathrm{Cu}_{2} \mathrm{O}$ phase; no peaks of other oxide phases were detected (Fig. 4). Accordingly, SEM images of this sample shows the uniformity of the spherically nanosized $\mathrm{Cu}_{2} \mathrm{O}$ (Fig. $\left.5 \mathrm{~A}\right)^{6,14}$. These $\mathrm{Cu}_{2} \mathrm{O}$ particles have the mean diameter of 30-40 nm (Sample 6). An increased amount of $\mathrm{HCOOH}$ facilitates to the formation of both cuprous and cupric oxides with different morphologies as elucidated by Fig. 5B. In the later, the as-obtained $\mathrm{Cu}_{2} \mathrm{O}$ is likely composed of coral-like architecture ${ }^{12,15}$ with diameters of around 1-2 $\mu \mathrm{m}$ as seen Fig. 5B.
The coral-like morphology is consisted of self-assembled nanorods (Sample 8$)^{7,15}$. Meanwhile, there appears of some nanobars with the smooth surfaces as if copper oxide is formed (Figs. 4 and 5B). This is in good accordance with what observed in sample 5 (Fig. 2D), but no metallic copper is detected in this case (Sample 8).

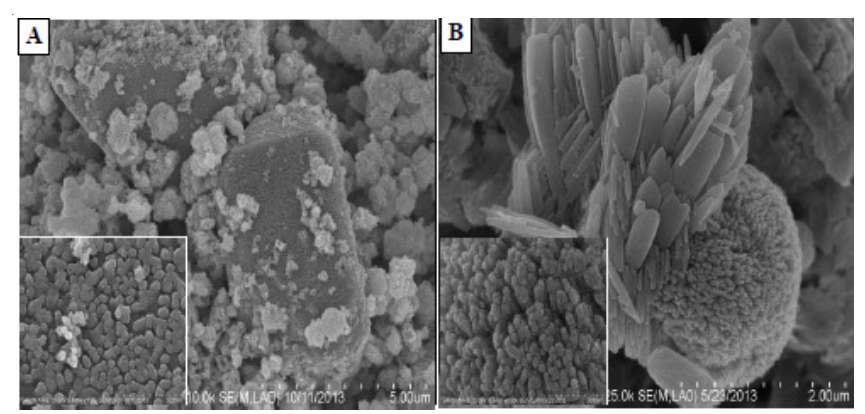

Fig. 5. SEM photographs of sample 6 (A) and sample 8 (B)

\section{Conclusion}

The present work has developed the hydrothermal oxidation-synthesis of mixed copper oxides, especially $\mathrm{Cu}_{2} \mathrm{O}$ nanostructures from copper powder with $\mathrm{H}_{2} \mathrm{O}_{2}$ aqueous solution. Under reported reaction conditions, nanostructured oxides are formed in different morphologies including nanospheres, nanostrips, nanorods, nanoplates, nanobars. The influences of aging time and the additive on the morphologies of $\mathrm{Cu}_{2} \mathrm{O}$ have been investigated. The yield of copper oxides and the product morphology are significantly increased with the presence of $\mathrm{HCOOH}$ additive. A single phase and the defined particle shapes of cuprous oxide are achieved if controlled reaction parameters such as aging time and the amount of additive. The synthetic method may be applicable to synthesize nanostructures of other metal oxides.

\section{ACKNOWLEDGEMENTS}

The authors thanks to Mr. Bui The Thien (QH. 2010) for his assistance.

\section{REFERENCES}

1. H. Xu, W. Wang and W. Zhu, J. Phys. Chem. B, 110, 13829 (2006).

2. Y. Chang, J.J. Teo and H.C. Zeng, Langmuir, 21, 1074 (2005).

3. H. Zhang, D. Zhou, L. Zhang, D.-F. Zhang, L. Guo, L. He and C.-P. Chen, J. Nanosci. Nanotechnol., 9, 1321 (2009).

4. M.A. Shoeib, O.E. Abdelsalam, M.G. Khafagi and R.E. Hammam, Adv. Powder Technol., 23, 298 (2012).

5. J. Zhang, J. Liu, Q. Peng, X. Wang and Y. Li, Chem. Mater., 18, 867 (2006).

6. H.Y. Zhao, Y.F. Wang and J.H. Zeng, Cryst. Growth Des., 8, 3731 (2008).

7. N.T. Thao, VN J. Chem., 51(3B), 500 (2013).

8. X. Zhang, J. Song, J. Jiao and X. Mei, Solid State Sci., 12, 1215 (2010).

9. G. Li, L. Jiang, S. Pang, H. Peng and Z. Zhang, J. Phys. Chem. B, 110, 24472 (2006).

10. M. Fernandez-Garcia, A. Martínez-Arias, J.C. Hanson and J.A. Rodriguez, Chem. Rev., 104, 4063 (2004).

11. S. Yin, S. Akita, M. Shinozaki, R. Li and T. Sato, J. Mater. Sci., 43, 2234 (2008).

12. Y. Dong, Y. Li, C. Wang, A. Cui and Z. Deng, J. Colloid Interf. Sci., 243, 85 (2001).

13. X. Zhang, G. Wang, H. Wu, D. Zhang, X. Zhang, P. Li and H. Wu, Mater. Lett., 62, 4363 (2008).

14. Z.C. Orel, A. Anzlovar, G. Drazic and M. Zigon, Cryst. Growth Des., 7, 453 (2007).

15. X. Xu, S. Sithambaram, Y. Zhang, C.-H. Chen, L. Jin, R. Joesten and S.L. Suib, Chem. Mater., 21, 1253 (2009). 